\title{
Os Corpos Insensatos de Laurent Goldring
}

\author{
The senseless bodies of Laurent Goldring \\ Dr. Osvaldo Fontes Filho \\ Professor no Dep. de História da Arte e no Programa de Pós-Gradu- \\ ação em História da Arte da UNIFESP - Campus Guarulhos \\ E-mail: osvaldo.fontes@unifesp.br \\ ORCID: http://orcid.org/0000-0002-2358-3902
}

\section{RESUMO:}

Este artigo expõe alguns elementos condicionantes do trabalho de Laurent Goldring em torno da representação do corpo cênico. Artista influente na renovação da videografia e coreografia dos últimos 20 anos, Goldring articula particular espaço de expressão, entre fotografias e vídeos, no qual - corpo humano aparece em uma estranheza renovada, para não dizer alucinante, por força da desconstrução de suas habituais posturas e simbolizações. É examinado ainda o reflexo de suas imagens em algumas arquiteturas coreográficas recentes.

Palavras-chave: Corpo. Fotografia. Vídeo. Dança contemporânea.

\section{ABSTRACT:}

This paper attempts to show some conditioning factors of Laurent Goldring's work focused on the representation of the scenic body. As an influential artist in the renewal of the videography and choreography in the last 20 years, Goldring articulates a particular space of expression between photographs and videos, in which the human body appears in a renewed, not to say mind-blowing strangeness, by means of a deconstruction of its habitual postures and symbolizations. It is also presents an analysis of the reflection of his images in some recent choreographic architectures.

Keywords: Body. Photograph. Video. Contemporary dance.

Artigo recebido em: 07/05/2019

Artigo aceito em: 19/07/2019

FONTES FILHO, Osvaldo. Os Corpos Insensatos de Laurent Goldring

PÓS:Revista do Programa de Pós-graduação em Artes da EBA/UFMG. V.9, n.18: nov.2019

Disponível em < https://eba.ufmg.br/revistapos $>$

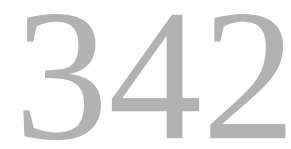


A representação do corpo, em suas idealizações clássicas, tende a articular suas diferentes partes, segundo uma hierarquia das funções: são os órgãos, em sua funcionalidade, que modelam a hominização das posturas e dos gestos que comumente organizam o todo. Assim, a mão e os dedos indicam; os braços apenas os sustentam. A cabeça entroniza uma verticalidade de bom alvitre, que os pés parecem negar em sua horizontalidade simiesca. O conjunto braço / mão, linha em variação perpétua, distingue-se o mais que possível de um torso que se quer em rigidez majestática. O corpo proporcionado parece se manter como inamovível imperativo de harmonia. Mesmo que se vivencie, hoje, uma extraordinária circulação de imagens provenientes das culturas populares, um acesso irrestrito ao patrimônio universal da representação, por força da iconosfera reinante, uma dominância parece paradoxalmente se manter: o desencorajamento das sensibilidades, contrariamente ao que se proclama, a elaborar suas próprias disfunções, suas desorganizações corporais.

Ainda que a arte, por vezes, se resigne a refletir modelizações de momento - a promoção das genitalia, no passado recente, das transsexualidades, atualmente -, ela é capaz de fazer vacilar as evidências perceptivas. Uma impressão de estranhamento pode bem provir de uma ínfima variação das posturas, de um espaço sem direções definidas, de movimentos insignificantes que façam com que os órgãos permutem suas aparências, escamoteiem suas evidências funcionais. Haverá, então, que se falar de um questionamento das hierarquias que organizam o corpo humano. Hierarquias que comumente as imagens analógicas (foto, cinema, vídeo) procuram legitimar em sua dominância comercial. Normalmente, uma cabeça não flerta com as partes baixas, os ombros não se assemelham a um órgão fálico, uma mão não cumpre as funções de um pé. Todas essas oposições estruturais, uma secular axiologia, são perfeitamente impeditivas do olhar ao premeditar as reações escópicas, ao antecipar as ações que um corpo expressivo tomará em uma ou outra situação. Imagens previsíveis é o que comumente propõem as cenografias para o grande público, ainda que um "princípio normativo de inclusão", constitutivo do regime representativo das artes, tenha segura-

FONTES FILHO, Osvaldo. Os Corpos Insensatos de Laurent Goldring

PóS:Revista do Programa de Pós-graduação em Artes da EBA/UFMG. v.9, n.18: nov.2019

Disponível em < https://eba.ufmg.br/revistapos $>$

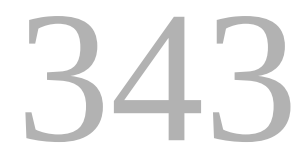


mente se ampliado generosamente nos últimos tempos, mas que continua a trabalhar com princípios de verossimilhança, conveniência ou correspondência, com critérios de distinção entre ações e seus efeitos dramáticos (RANCIÈRE, 2005, p. 31).

Ocorre algo de diverso nos vídeos e imagens fotocoreográficas que compõem a série Petite chronique de l'image (1995-2002) do artista visual e coreógrafo francês Laurent Goldring. Exibida, em 2002, no Centre Georges Pompidou de Paris, e, em seguida, integrada a seu acervo, ${ }^{1}$ esse trabalho trai uma resoluta vontade de não premeditar visões e, com isso, surpreender o corpo em uma espécie de desarranjo estrutural notável, em uma desorganização capaz de renovar o sobrecodificado motivo do nu artístico.

Os corpos que surgem das imagens de Goldring, em sua maioria de dançarinos profissionais, fazem parte de um trabalho já de algumas décadas em torno de perturbações da representação do corpo cênico, um corpo que se quer apartado de toda dramaturgia, de toda narração, ou da filosofia redutora da semelhança, nos limites do reconhecimento. Para tanto, suas figuras recebem uma iluminação que as destaca do fundo escuro, modo de acentuar posturas em variações ínfimas, à beira do improvável, e que solicitam um tempo investigativo do olhar. Esse é, assim, instado a construir e desconstruir pouco a pouco a imagem, em silencioso embate com os pressupostos da ideia de organicidade. Corpos em enquadramento serrado, fechados em seus nichos cênicos - reminiscência do espaço cilíndrico em estreitamento do Dépeupleur (The Lost Ones) de Samuel Beckett (CHARLIN, 2002, p.74) -, se extraem, assim, da escuridão ambiente "como de um líquido amniótico, parecem emergir da imagem como pela primeira vez" (PLANTIN, 2017, não paginado). Goldring fala dessas imagens carregadas de certo primitivismo em termos de volteios / circuitos ("boucles"), acentuando o viés incoativo de suas figuras. Cada um dos vídeos iterativos apresenta apenas um corpo nu animado por gestos por vezes sutis, micromovimentos repetidos com ínfimas variações, evocando espasmos, tremores ou pulsões. Eles parecem,

FONTES FILHO, Osvaldo. Os Corpos Insensatos de Laurent Goldring

PóS:Revista do Programa de Pós-graduação em Artes da EBA/UFMG. v.9, n.18: nov.2019

Disponível em < https://eba.ufmg.br/revistapos $>$

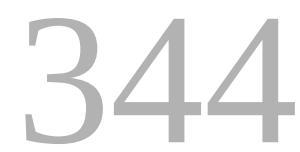


assim, verter tensões e agitações internas à superfície, como se vindas dos próprios órgãos. Esses não se identificam imediatamente como tais. Pode ocorrer de um joelho se assemelhar a uma cabeça, ou que os membros superiores se ausentem; ocorre mesmo de a visão tardar a se aperceber do alto e do baixo de um corpo focalizado. As próprias posturas, comumente em palpitação, convidam a que se tome o corpo como um único órgão, e não como um organismo articulado em formas legíveis e identificáveis como ocorre na tradição do nu. As figuras de Goldring criam, pois, as condições de uma indistinção entre a parte e o todo, um membro e outro, um sólido e um vazio; indistinção que é mesmo sentida ao ponto da identidade sexual. A dessemelhança visa uma emergência improvável do real; é ela o sujeito da imagem fotográfica. Inversão mesma da mimesis: “é o corpo que irá se assemelhar à imagem em curso de realização, não a imagem que será semelhante ao modelo eleito" (DEBAT, 2009, p. 71). Como consequência, o artista questiona o estatuto da imagem do corpo à luz da história da fotografia e, mais diretamente, da imagem-vídeo.

Goldring entende considerar suas imagens como processualidades circulares, antes de analisá-las como representações arrematadas. Com o que elas perdem a faculdade de controlar e reorganizar a relação de si a si. Procedimentos de criação são assim idealizados em favor de uma imagem "em formação" do corpo:

Durante o trabalho, é uma questão de olhar para a imagem, ver onde ela se desassemelha e depois continuar retirando tudo o que nos impede de ver essa dessemelhança. Olhar para uma imagem de corpo, em geral, é um tipo de percepção muito global: vemos imediatamente um corpo, vemos uma perna, um braço, alguém velho, alguém bonito, estas são de imediato significações, imagens que já estão ali [...] Concretamente, é preciso refinar a postura para limpar a imagem do que impede ver: um braço, por exemplo, nunca se detém no ombro, pode continuar até a cintura, ou até a ponta do cotovelo, mas se não trabalhamos a forma da mão, o olhar irá imediatamente restaurar a visão codificada, que tomará todo o lugar (GOLDRING, 2002, p. 77; tradução nossa).

FONTES FILHO, Osvaldo. Os Corpos Insensatos de Laurent Goldring PÓS:Revista do Programa de Pós-graduação em Artes da EBA/UFMG. V.9, n.18: nov.2019 Disponível em < https://eba.ufmg.br/revistapos $>$ 
Nos video loops de Goldring, corpos larvares estão de algum modo comprometidos com a sombra, com o indefinido; seus pontos de apoio se situam em algum lugar de um espaço adimensional, de modo que a visada da câmera se abisma nos escorços ou, ao contrário, nas expansões de volumes. Por vezes, o que se vê é o traçado de uma coluna vertebral que se sobressai abruptamente, uma torção incomum dos pés em primeiro plano, uma cabeça que se afunda no peito ou um joelho que disputa com o crânio um despontar das sombras. Pedaços mal identificados no distanciamento de uma perspectiva em fuga: o caimento de uma nádega que se estira na negação de sua protuberância, as dobras de um tronco que se retorce e despenca ao chão na ausência da cabeça, o movimento angustiante de uma omoplata, o esmagamento de uma panturrilha, a ofegância que as costelas insinuam, ou mesmo o fremir de uma epiderme devolvida a suas rugosidades usuais. Goldring preconiza que o corpo representado passe por "intensidades de existências que são ao mesmo tempo deformações, protomovimentos que o sustentam" (GOLDRING, 2002, p. 79). Sem direção nem intenção, esses frêmitos "ocorrem no interior do corpo e da forma que este assume"; mais que apontar para séries de deformações progressivas, esses movimentos indicam a possibilidade de um corpo diverso, "ali onde a figura humana se desagrega" (GOLDRING, 2002, p. 79). Para tanto, decisões são negociadas entre o artista e seus modelos com base na imagem de um monitor de controle: a tela, contrariamente ao "visor caolho" do cinema, que permite "reconhecer apenas o que já se conhece" (apud DEBAT, 2008, p. 120), não é mera superfície de inscrição, de representação, mas território de diálogo com a imagem em formação, zona de encontro entre intencionalidades diversas, entre o possível e o desconhecido. Goldring explica seu método de trabalho:

[...] dentre os diferentes modelos (paradigmas) que tinha à disposição para entender o ato de filmar (encenação, direção de atores, coreografia etc.), nenhum era operacional, todos se mostravam obstáculos. Nesse protocolo havia a ideia de trazer ao corpo algo de muito pessoal, de muito particular para a pessoa com quem trabaIhava. Em seguida, esses dançarinos-coreógrafos podiam aproveitar totalmente o que eu havia feito com ele em vista de colocá-lo no palco. Tive a sorte de poder trabalhar com performers prontos para

FONTES FILHO, Osvaldo. Os Corpos Insensatos de Laurent Goldring

PÓS:Revista do Programa de Pós-graduação em Artes da EBA/UFMG. V.9, n.18: nov.2019 Disponível em < https://eba.ufmg.br/revistapos $>$

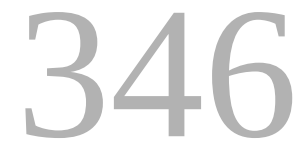


reinjetar com sua própria subjetividade todo o trabalho extremamente objetivo que havia sido feito a montante. O engajamento era o de produzir uma crítica em ato da ideia de que a representação [do corpo] estaria esgotada. Ao me interrogar sobre o que se via nas imagens que estava produzindo (tudo que faço consiste em me colocar à escuta e em aprender com as imagens que estou fazendo), e sobre o que isso significava para as próprias imagens, fui levado a me interrogar sobre o que me parecia novo, tanto em termos de imagens como de corpos. (GOLDRING, 2012, p.115; tradução nossa)

Os meios técnicos para a renovação dos arcaísmos fisiológicos são muito simples, e referem uma tradição fotográfica e escultórica - a iluminação concentrada, o corpo como volume a ser rodeado ou frontalizado -, e uma práxis de poses que derivam mais da postura do que da posição - “a postura, precisa Deleuze (apud GOUMARRE, 2002, p. 44), é um suspense invertido, que não espera outra resolução que ela própria". Não há, pois, aqui referência alguma a qualquer tipo de indicialidade fotográfica ou psicológica. O corpo aparece num estranho e hesitante trânsito entre a imobilidade e o movimento. Sutilmente espasmódico, ele exige que o observador tome o tempo devido a fim de (re)construir mentalmente e temporalmente suas representações metamórficas assentadas em uma carnalidade cujos pontos de referência escasseiam. Importa, aqui, uma vez mais, e de modo mais extenso, reter alguns esclarecimentos de Goldring quanto a seus procedimentos de criação:

Quando algo aparece no monitor, começo a dar indicações destinadas não a fabricar algo, mas a permitir ao olhar focar sobre o que está em vias de se desenhar. Se uma posição de perna, uma forma de braço, uma linha de ombro me parece poder figurar na origem de uma imagem, então peço ao dançarino para se deter nessa posição, para que ele produza uma espécie de enredamento (boucle) sobre si mesmo; peço que repita esse movimento até fazer desaparecer os elementos que impedem ver o que é interessante: uma perna não se assemelha a uma perna, isto é, uma perna não se assemelha à imagem habitual que se pode ter de uma perna. Ao nível do corpo, algo se passa: o prazer de fazer. Há um momento em que, na imagem e na posição que é assumida para que essa imagem se faça possível, a pessoa é tomada de um efeito de reconhecimento. Como se o que ela reconhecia fosse outro corpo possível que poderia ter fabricado [...] Procura-se colar às imagens [...] Aqui, em lugar de se fabricar seu corpo sobre imagens exteriores, ele é construído em função de imagens interiores, e é quando se toca seus outros corpos

FONTES FILHO, Osvaldo. Os Corpos Insensatos de Laurent Goldring PÓS:Revista do Programa de Pós-graduação em Artes da EBA/UFMG. V.9, n.18: nov.2019 Disponível em < https://eba.ufmg.br/revistapos $>$ 


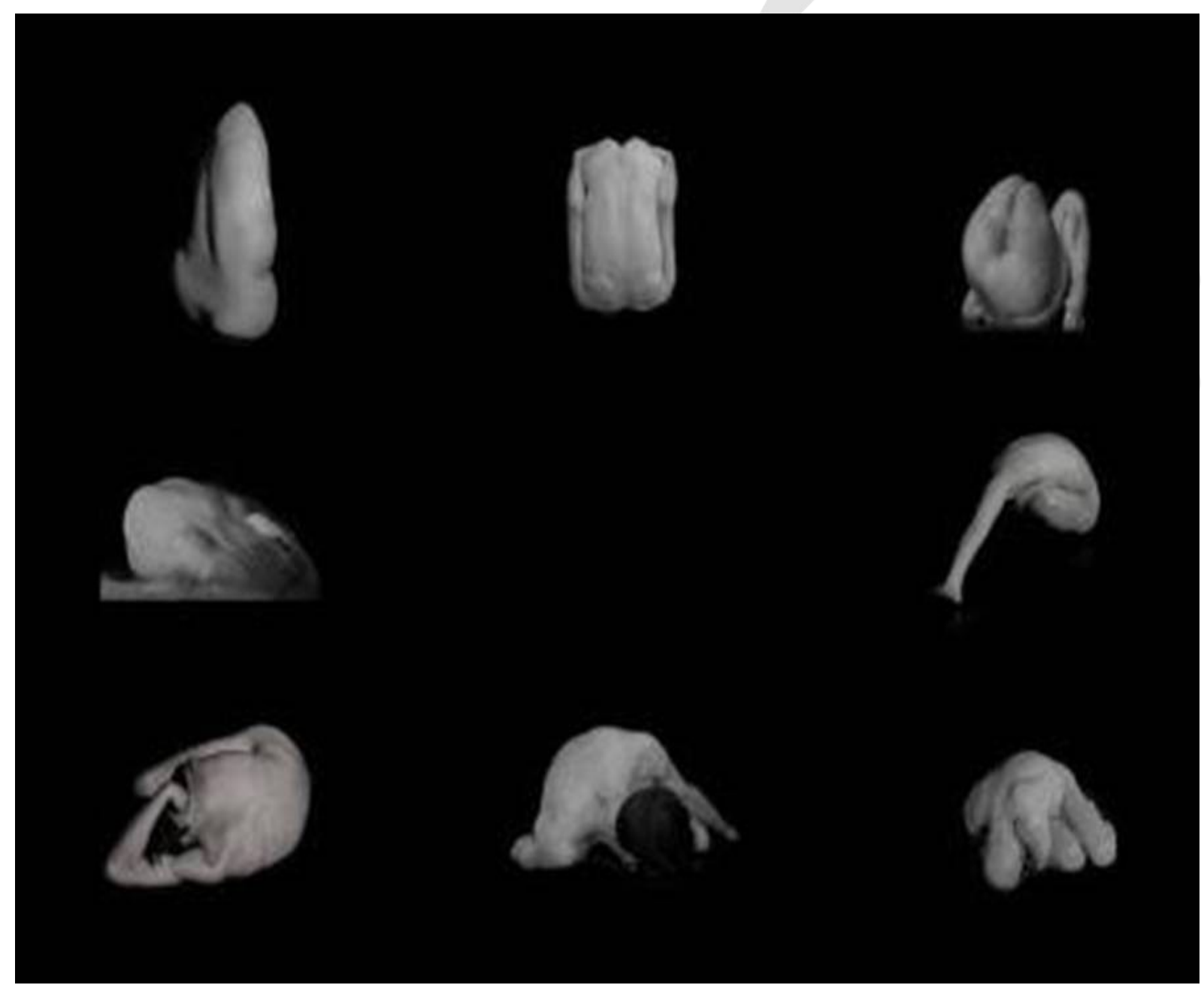

Figura 1 - Laurent Goldring, Petite Chronique de l'image, stills de vídeos - 1995-2002

Fonte: https://www.centrepompidou.fr/cpv/resource/cy75zg/rEBGgro.

possíveis que foram postos de lado, rechaçados, quando se dá conta disso, quando algo pode novamente emergir, é então que a imagemcorpo se torna viva.

A partir de então, minhas microindicações para posicionamentos, extremamente minuciosas, deixam de ser necessárias, como se esse corpo tivesse tomado pulso e pudesse viver uma vida completamente autônoma. É o momento em que, enquanto coreógrafo, tornase possível utilizá-lo em outro lugar, em cena, dele me apropriar. Nesse processo, terão ocorrido dois tempos: de início, uma lógica da estranheza, "não sou eu esse corpo que enxergo, nunca me vi assim"; depois, esse corpo possível que emerge, "esse não pode ser outro senão eu". É um momento de reapropriação forte, o critério

FONTES FILHO, Osvaldo. Os Corpos Insensatos de Laurent Goldring

PÓS:Revista do Programa de Pós-graduação em Artes da EBA/UFMG. V.9, n.18: nov.2019

Disponível em < https://eba.ufmg.br/revistapos $>$ 
para que dê por encerrado o trabalho: a revelação de um corpo subjetivo e o alcance da imagem de um corpo universal que diz que os órgãos não de detém lá aonde se pensa, que um braço não existe sozinho, mas prossegue nas costelas, que um braço é a mesma coisa que uma perna, os ombros a mesma coisa que as nádegas (GOLDRING, apud GOUMARRE, 2002, p. 42; tradução nossa).

O artista e seus dançarinos funcionam sem qualquer modelo reconhecido, no interstício entre fotografia, dança e vídeo, em lâminas de tempo que mal separam o instantâneo do duradouro. Do lado do gesto e do movimento, ou da pausa e da respiração, eles trabalham nos intervalos dos possíveis. Daí o efeito alucinante provocado por essas imagens: um corpo ainda desconhecido nos é apresentado, de volumetria um tanto insensata, não mais feita de superfícies e formas conhecidas, mas de massa e tensão, dobras e expansões animadas por forças desconhecidas. Uma "desorganização pré-motriz", dir-se-ia, "anatomias destruídas, contornos perdidos, imagem que se esquece de si mesma em sua própria não-forma" (LOUPPE, 2002, p. 48). Vistos em conjunto (FIGURA 1), esses corpos assemelham-se a restos perturbadoramente orgânicos, presos em atos desesperados de corporificação, de escape de seus limites fisiológicos, em esforços para se reinventarem para além de toda narrativa individual e toda história coletiva.

Semelhantes a supliciados, as figuras de Goldring parecem condenadas, pelo ritmo iterativo dos vídeos, a continuar indefinidamente seus movimentos repetitivos. Seus esforços parecem malograr numa oscilação hesitante, numa estagnação quase mecânica. "Agitação vã e bloqueada [...], espécie de imobilidade fervilhante e barulhenta. [...] O fracasso das metáforas e ficções que não vingam entrega essas imagens a seu próprio mutismo" (CHARLIN, 2002, p. 75). Inevitavelmente, o olhar que as examina, que mergulha em seus nichos sombrios, torna-se investigativo, rastreador mesmo: o que motivaria esses corpos a se agitarem? que catástrofe iminente torna seu trabalho tão febril? que animal ali se encontra, teimosamente se remexendo em torno de si mesmo?

FONTES FILHO, Osvaldo. Os Corpos Insensatos de Laurent Goldring

PÓS:Revista do Programa de Pós-graduação em Artes da EBA/UFMG. V.9, n.18: nov.2019

Disponível em < https://eba.ufmg.br/revistapos $>$

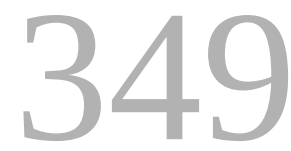


Fato é que as figuras criadas pelo arranjo videográfico e performativo de Goldring mostram-se estranhamente suspensas entre o humano e o animal, entre o feminino e o masculino, entre o banal e o surreal. Para uma corporeidade assim proposta bem se poderia adotar o apelativo deleuziano "corpo-sem-órgãos", mesmo porque ela transita pela multiplicidade dos modos e das formas: verme rastejante, matéria deliquescente, deformação desossada, dobra e inchaço, retração e distorção, destroços dispersos. Um desafio à lógica do visível, de seu entendimento e ordenamento: o quadril briga com o tronco, a cabeça com os pés: toda compostura, aqui, se furta. Em uma das versões mais contundentes dos vídeos em looping de Goldring, Sculpture móbile \#16 (2013)², uma calota (craniana?) de carne viravolteia na demonstração inequívoca de um pulsar um tanto perturbador. Em Sculpture móbile \#7 (2000) ${ }^{3}$, a câmera fecha o foco longamente em mãos e pés que parecem repensar suas funções e propor inusitadas reciprocidades. Para Goldring, a hipótese recorrente do esgotamento da representação do corpo não se sustenta: ainda não sabemos o que pode um corpo e o que o olho ali ainda tem a descobrir. Longe das práticas desencantadas de um ser vencido e abandonado, este trabalho flerta sem ingenuidade com as possibilidades de subverter a forma, até o informe, prerrogativa-base de um modernismo crítico dos antropomorfismos, desde os manequins surreais de De Chirico ou as bonecas desarticuladas de Hans Bellmer aos rebaixamentos orgânicas de Georges Bataille.

Nesse tocante, a abordagem de Laurent Goldring assemelha-se à pesquisa realizada por uma nova geração de coreógrafos franceses que de algum modo lhe são tributários: Alain Buffard, Xavier Le Roy, Benoît Lachambre, Maria Donata d'Urso, Louise Lecavalier em algum momento movimentaram em suas performances cênicas a heurística que Goldring propõe para o corpo. Já em 1999, Jacqueline Caux interpelava essa obra a partir de sua nomenclatura: falar em termos de bodymade implicaria, de imediato, fazer surgir um conjunto de representações e problemáticas, "ressaltos estéticos e filosóficos" passíveis de serem propostos a partir dos êxitos e malogros do ready made duchampiano, assim

FONTES FILHO, Osvaldo. Os Corpos Insensatos de Laurent Goldring PóS:Revista do Programa de Pós-graduação em Artes da EBA/UFMG. V.9, n.18: nov.2019 Disponível em < https://eba.ufmg.br/revistapos $>$ 
como das diversas tendências da body art. Efetivamente, o trabalho de Goldring multiplica interpelações: como objetivar o corpo nu, evacuando as simbolizações massivas que a este estão comumente associadas? como manter na pratica da criação o questionamento do estatuto de sua representação? como administrar um espaço de expressão que estaria na junção/disjunção entre foto grafia, vídeo e pintura? De imediato, diga-se que as espacialidades incoativas, as encenações minimalistas dos bodymade de Goldring insinuam uma renovada temporalidade da imagem móvel, ao mesmo tempo em que fazem surgir inesperadas reminiscências picturais e escultóricas. Desse ponto de vista, o bodymade constitui um trabalho que parte do fotográfico enquanto possibilidade de refiguração e de deslegitimação da representação. Assim se expressa, a respeito, Goldring:

Ao escolher a palavra bodymade, eu designava também o fato de não me ater a uma natureza do corpo, mas a algo completamente informado, fabricado. Não há transformação do corpo em obra, mas demonstração do que em um corpo excede a fabricação, o que Bataille chama de "a insurreição dos órgãos". Não se trata de transformar o corpo em obra, mas sim de desobrar uma história da representação. De repente, de modo inesperado, vemos surgir um Bacon, um Bosch, um Moore: eles desaparecem como assinatura e se mostram como possibilidade fotográfica do corpo. Nunca se dirá suficientemente a que ponto a história da arte moderna é a história de seu confronto com a imagem fotográfica. Meu trabalho implica desconectar o corpo. Não é um trabalho ao nível do simbólico, mas ao nível do imaginário que, sem a mediação do simbólico, pode bascular para o real. (GOLDRING, 1999, p.40; tradução nossa)

“Desobrar uma história da representação". O intento, com a conotação revisionista que o verbo sempre carregou - de Blanchot (2007) a Agamben (2017) -, implica assumir particular relevo para o registro fotográfico. Para além do inevitável efeito de reverberação de um conhecido repertório imagético - quiçá impregnado nas cinestesias do espectador ocidental, ou então motivado pela inequívoca natureza palimpséstica das imagens em P\&B de Goldring -, esse é um trabalho de insurreição que aposta no esvaziamento das expectativas e das preceptivas. Ao fotográfico, pois, de registrar em sua devida riqueza um esforço

FONTES FILHO, Osvaldo. Os Corpos Insensatos de Laurent Goldring

PóS:Revista do Programa de Pós-graduação em Artes da EBA/UFMG. v.9, n.18: nov.2019

Disponível em < https://eba.ufmg.br/revistapos $>$ 
de fuga das convenções (do corpo configurado pela sociedade e pela representação), esforço em procurar o corpo para além de suas grafias confirmadas. Um corpo primitivo por assim dizer, irreconhecível de imediato, que flerta mesmo com a abstração. Se os volumes das imagens de Goldring tomam lugar em um espaço totalmente neutro, o que garantiria a princípio alguma leitura do desenho, a pele "como que se encarna no grão da fotografia, se faz matéria pictural [...]; a imagem não é uma superfície lisa, ela se faz tátil" (PLANTIN, 2017, não paginado).

No convite a uma imersão indagativa, e na ausência de qualquer linha narrativa, os vídeos de Goldring, já se disse, abrigam micromovimentos repetitivos; eles mimetizam, assim, a circularidade, o enredamento sobre si do corpo focado. Tanto nas fotos quanto nos vídeos, o corpo parece assumir dimensão escultural densa, compacta. Linha dos ossos, saliência dos músculos, alongamento ou contração das fibras: o corpo existe ali em toda sua materialidade, em sua densidade de massa. Entretanto, não se vê aonde assenta seu peso. Ele "flutua em território abstrato, isola-se no espaço e no tempo" (PLANTIN, 2017, não paginado). O nó, o enredado/trançado (a boucle), impõe-se como a forma mais adaptada a um olhar em perda de suas balizas habituais, que se esgueira então de modo não premeditado, errático. Os inframovimentos, micro-oscilaçoes quase estáticas, produzem gestos incompatíveis que a repetição reúne na visão de um corpo improvável que substitui a figura humana para se instalar como sua possibilidade mais rica. Os video loops oferecem, então, uma experiência visual que o tempo vem densificar. Tempo que não se inscreve nem no passado do clichê fotográfico ortodoxo, nem no futuro de desfecho narrativo ao qual convida comumente a imagem cinematográfica. O olhar em circularidade forçada é experiência de um presente sem ruptura, que integra como bem entende a acumulação das metamorfoses. Ele nem anula as metamorfoses múltiplas do real, o que faz o fotográfico com seu "instante decisivo", sua pretensão à semelhança, nem as condiciona a uma resolução feliz ou inevitável, o que faz o rumor roteirizado dos fotogramas do cinema. Nesse sentido, as imagens retidas dos vídeos, os foto-

FONTES FILHO, Osvaldo. Os Corpos Insensatos de Laurent Goldring

PóS:Revista do Programa de Pós-graduação em Artes da EBA/UFMG. v.9, n.18: nov.2019

Disponível em < https://eba.ufmg.br/revistapos $>$

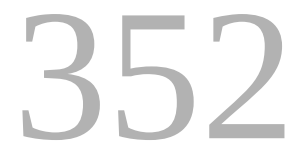


gramas que constituem a galeria de figuras da Petite chronique de l'image - "movimento suspenso de imagens filmadas conduzidas à estase fotográfica" (LOUPPE, 2002, p. 48) - conservam a espessura de tempo constitutiva dos video loops enquanto processualidades investigativas dos corpos. É como se as granulações do fotográfico continuassem a palpitar, como se guardassem na imagem fixa as pulsações registrados no vídeo. Vê-se como a atitude suspensiva do gesto em Goldring, a ordem do tempo submetida à escansão do espaço, observa a injunção central da contemporaneidade para seus modos expressivos: substituir o movimento ao discurso, em favor de uma “intensidade imemorial do corpo irredutível à ordem da narrativa tanto quanto àquela da convenção social que funda essa narrativa". (VOLLAIRE, 2006, não paginado)

Nos vídeos de Goldring depositam-se investidas nada dogmáticas do coreógrafo. Não somente porque seus modelos são, invariavelmente, dançarinos e/ou coreógrafos (afeitos, pois, ao questionamento de seus corpos). Mas, sobretudo, porque um tempo sem narração faz valer procedimentos assemelhados àqueles da dança contemporânea, nos quais o que importa é deixar aparecer e, sobretudo, postergar esse aparecer, refazê-lo a cada vez diferentemente. Visa-se com isto o oposto de um corpo metaforizado. O corpo questionado da dança contemporânea não representa mais que a própria redundância, razão porque é na repetição que ele encontra sua intensidade. Por ser a entidade pulsional que fornece visibilidade ao desejo, o corpo dançado “abandona sua dimensão metafórica para aceder a uma dimensão metonímica: o valor coreográfico do corpo do dançarino não se sustenta senão do fato de ser a representação de todo corpo [de desejo]" (VOLLAIRE, 2016, não paginado). Em entrevista a Jacqueline Caux, Goldring sinaliza o que lhe provém da dança, nesse intento circular junto a gestos primevos, rumo ao que denomina "movimento primeiro":

A dança aplaina toda trajetória para apagar o suporte orgânico, enquanto [um] movimento para aquém do movimento cria um corpo que ainda não se move, mas que é capaz de fazê-lo em um espaço que ainda não existe, mas que é capaz de surgir. As restrições formais ao nível do movimento implicam, portanto, certa forma de

FONTES FILHO, Osvaldo. Os Corpos Insensatos de Laurent Goldring PÓS:Revista do Programa de Pós-graduação em Artes da EBA/UFMG. V.9, n.18: nov.2019 Disponível em < https://eba.ufmg.br/revistapos $>$ 
cenografia, ou de encenação, que deve se empenhar para obter no registro do espaço da cena a mesma redução que obtém do corpo [...] De repente, o informe toma forma, a forma simplesmente se apresenta. Trata-se de uma modalidade de presença que não implica nenhuma ausência, a ausência de [referente] deixa de ser sentida como tal. A imagem detém então todo o seu conteúdo (GOLDRING, 1999, p. 42; tradução nossa).

O surgimento de uma temporalidade que subverte a essência do espetáculo como premeditação de uma forma põe em risco o corpo nas mais diversas formas de desnaturação. É o que implicam todas as atitudes assumidas de suspensão do tempo ou de decomposição do movimento. "Se a pose é a suspensão do tempo no instante, a postura é a suspensão do possível na extensão do tempo da imagem" (DEBAT, 2009, p. 72). Goldring, nesse tocante, não deixa de reivindicar a herança das cronofotografias de Étienne-Jules Marey a expressão "movimento primeiro" é justa referência ao "cinema primeiro" de Marey e dos Irmãos Lumière que, no interstício entre imagem fixa e imagem em movimento, inventaram um médium e um modo de perceber o real. Mas Goldring não ignora que, para além de dimensões indecidíveis e indiferenciadas do corpo, suas imagens não deixam de manifestar certa precariedade da figura humana. Mesmo porque, o corpo é aqui convocado a uma desregrada dinâmica de circulação dos influxos nervosos. Razão porque ele se fabrica uma imagem que privilegia o trajeto visual entre suas partes, na deriva de todo curso de reconhecimento dos possíveis humanos. Um corpo cênico "pós-humano" conhece uma genealogia antiga, que passa por Loïe Fuller, num arco que atravessa o século 20 e vem ter com as experimentações de Cunningham, de Yvonne Rainer, do Judson Dance Theater, da body art. De certo modo, as fotografias e vídeos constitutivos de Petite chronique de l'image, e as consequentes montagens videocoreográficas posteriores de Goldring, atualizam motivos debatidos desde os anos 1950 e 1970: a informalidade do gesto, a efemeridade da performance, o valor da improvisação, a precedência do processo sobre o produto, a fragilização da autoria, entre outros.

FONTES FILHO, Osvaldo. Os Corpos Insensatos de Laurent Goldring PóS:Revista do Programa de Pós-graduação em Artes da EBA/UFMG. v.9, n.18: nov.2019 Disponível em < https://eba.ufmg.br/revistapos $>$ 
$\mathrm{Na}$ perspectiva de sua fragmentação em série, o corpo em Goldring parece confirmar a revolução estética de que trata Rancière: uma “interminável ruptura com o modelo hierárquico do corpo, da história e da ação"; razão pela qual é possível inserir procedimentos expressivos como os de Goldring na "história de um regime da arte como aquela de um grande corpo fragmentado e da multiplicidade dos corpos inéditos nascidos dessa fragmentação mesma" (RANCIÈRE, 2011, p. 14). Essa história de fragmentação e disseminação é a parte mais visível de uma reformulação de base do que Rancière aponta como "os dois grandes critérios em uso na ordem representativa: primeiramente, a harmonia das proporções, ou seja, a congruência entre as partes e o todo; em seguida, a expressividade" (RANCIÈRE, 2011, p. 22). A história da neutralização da expressividade - e de seus corolários, a equivocidade de uma forma e a suspensão da narração - dá-se, garante Rancière, por correntes contraditórias ou temporalidades heterogêneas. Não se trata apenas de uma nova organização do corpo, como também das partes de uma obra. Seja como for, o trabalho de Goldring parece se inscrever sem maiores hesitações numa modernidade que, em registro rancieriano, trata de "inscrever o movimento do pensamento no movimento das formas". De fato, é nessa autorreflexividade do movimento - injunção basilar do modernismo- ${ }^{4}$ que Goldring formaliza seus procedimentos mais consequentes. Verdadeira heurística junto à tela, o intento de encontrar novos trajetos do olhar no corpo espreita a todo o momento as armadilhas da premeditação, que pode advir do lado da dança ou do teatro enquanto formas sobrecodificadas. Assim, ressalva Goldring (2002),

Nunca há tentativa de "fazer" uma imagem, nunca uma focalização ou um momento que se queira reproduzir, porque isso produziria movimentos muito restritos: a dança retornaria imediatamente, ou o teatro. [Cumpre] renegociar no corpo e na imagem as disrupções da representação que se pode constatar, sem lhes remover o caráter de acidente, no sentido de Dubuffet. $O$ acidente em Dubuffet é essa extrema labilidade dos corpos que, por um mínimo "acidente", deixam de se assemelhar: um retrato de mulher se torna um retrato de homem, muda de sexo porque um grão de preto não estava seco e o pincel ao arrastá-lo fez um bigode. O que, aliás, prova que um corpo somente tem um sexo por acidente (p. 78; tradução nossa).

FONTES FILHO, Osvaldo. Os Corpos Insensatos de Laurent Goldring

PÓS:Revista do Programa de Pós-graduação em Artes da EBA/UFMG. V.9, n.18: nov.2019

Disponível em < https://eba.ufmg.br/revistapos $>$

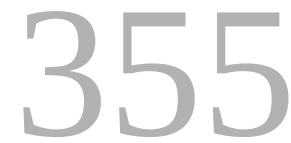


Como se vê, um corpo interpretado a partir de sua labilidade implica em recolocar em pauta a questão da semelhança. Ao remover a obrigação de dizer ou de representar algo, Goldring questiona todo imperativo de semelhança quando do ajuizamento de uma imagem: "o que faz com que uma imagem seja semeIhante, ou dessemelhante? [...] o que acontece quando se para de colar em um corpo ou em um rosto noções de semelhança? que noção é esta de "a que deve parecer"? (GOLDRING, 2012, p. 118). Respostas a tais indagações surgem internamente ao médium. Há aqui, esclarece Goldring, a intenção expressa de retomar uma posição modernista. Para o que vale, mesmo, a evocação de Cézanne: em sua especificidade maior: o monitor no qual o artista trabalha a imagem em sua processualidade - "ver ao mesmo tempo a imagem que desejo e aquelas que é preciso esquecer", de modo a pensar contra a perenidade do traço (GOLDRING, 2004, p. 148) -, assemelha-se a uma tela em branco, superfície de expurgo dos clichês, o que impõe o trato com a matéria mesma da imagem. No caso das imagens de Goldring, o trato com o corpo "como uma matéria pictural". Assim, uma imagem que se pensa em sua materialidade, uma imagem em enredamento sobre si, urde precisa processualidade:

[...] à força de recomeçarmos por formas completamente diferentes, cruzamos a um dado momento com formas já aparecidas, e sabemos melhor como lidar com elas. O corpo gira então ao redor de si mesmo, em frente à câmera, em todos os sentidos, à espera do momento justo, quando o corpo que está sendo construído mostrase "verdadeiro", isto é, quando ele corresponde àquele corpo com o qual trabalho. Pouco a pouco, algo foi construído, em termos de ritmo, de posturas, do imaginário ou do prazer corporal, e em um dado momento aí está... "Aí está" não significa o fim de um trabalho; é algo de retrospectivo; percebemos que "algo tinha ocorrido ali" enquanto olhávamos para as imagens. Esse "algo" pode então constituir uma sequência a ser posta em circularidade (GOLDRING, 2002, p.78; tradução nossa).

A perspectiva teórica de Jacques Rancière é aqui ratificada pela heurística de Goldring. O que ocorre no regime estético da arte é uma impossibilidade de evacuar a aparência: as coisas há muito deixaram de ser mudas; elas estão sempre de algum modo investidas de logos, ou melhor, incluídas num regime

FONTES FILHO, Osvaldo. Os Corpos Insensatos de Laurent Goldring PóS:Revista do Programa de Pós-graduação em Artes da EBA/UFMG. V.9, n. 18: nov.2019 Disponível em < https://eba.ufmg.br/revistapos $>$ 
de mercadoria. Sendo a aparência mais uma mercadoria, o artista se obriga o trabalho interminável de evacuação do olhar, com a tentação do informe no momento mesmo da formação. Razão porque Goldring afirma fornecer por vezes indicações de imagem que são verdadeiras "impossibilidades anatômicas", com o fito de uma reversão do regime ortodoxo das imagens: "não é a imagem que se assemelha ao corpo, é o corpo que se assemelha cada vez mais àquela imagem que ainda não está completamente aí, que está em vias de surgir e que já se pode entrever" (GOLDRING, 2002, p. 78-79).

Não surpreende surgir, no trato direto com a matéria, na exsudação, por assim dizer, das metáforas que maquiam a pele do corpo representado, o motivo de uma superação do humano. Não se está, contudo, em uma lógica do corpo ignóbil, replica Goldring, nem mesmo são visados achados formais que confirmem a nobreza ou a versatilidade do corpo humano. Trata-se, antes, de evacuar hábitos ou imposições de legibilidade:

\begin{abstract}
Está-se em outra dimensão, em um corpo que ainda não é humano, mas infra-humano, no lapso de tempo em que ele conseguiu se livrar da saturação dos signos que o constituem. Não há corpo humano fora dessa saturação de signos; é uma questão de fazê-los desaparecer sem fazer o corpo desaparecer. O corpo, legível antes de ser visível, deve ser tornado ilegível, impedido de enviar esses sinais, não pelo enunciado de um interdito, mas simplesmente "negociando" com a imagem os momentos em que ela não mais envia sinais; tempos rarefeitos que cumpre captar. O timing desses momentos põe fim à histerização, ao narcisismo, ao desejo de significar o que quer que seja com o próprio corpo (GOLDRING, 1999, p. 42; tradução nossa).
\end{abstract}

Uma corpografia desembaraçada das metáforas mostra o que do corpo resta: porções de visibilidade descontínua, detritos formais que se remexem, tanto no interior quanto no exterior, que se deslocam e se reagenciam de modo a assumir repentinas formas. Um "corpo desconectado, sem significâncias", desembaraçado de signos e temáticas (GOLDRING, 1999, p. 42), esvazia toda leitura renitente das metáforas. Goldring não ignora que diante de representações as pessoas urdem histórias, suas próprias metáforas: animais, vegetais, o

FONTES FILHO, Osvaldo. Os Corpos Insensatos de Laurent Goldring

PÓS:Revista do Programa de Pós-graduação em Artes da EBA/UFMG. V.9, n.18: nov.2019

Disponível em < https://eba.ufmg.br/revistapos $>$ 
que seja. Pode-se mesmo derivar rapidamente para significações mais pesadas, tudo quanto os afectos comuns de um corpo nu possam suscitar: monstruosi-

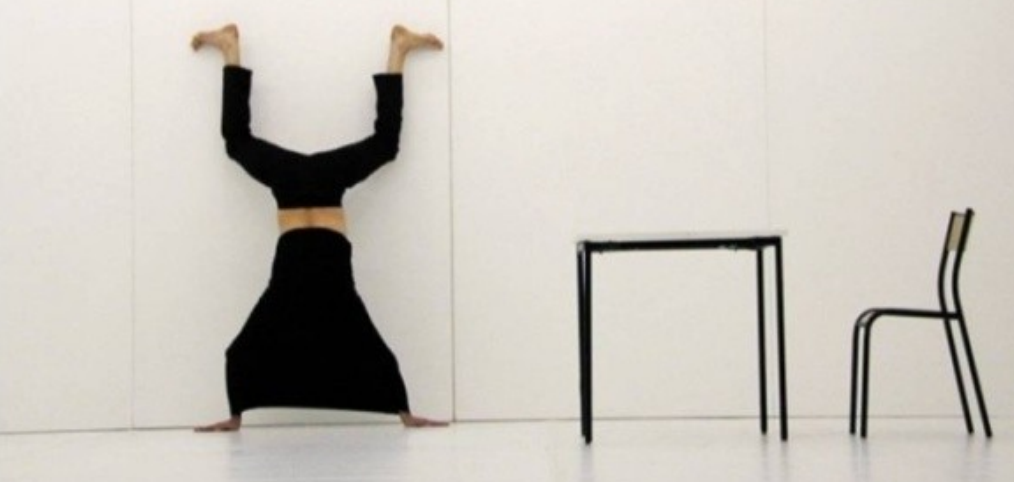

dades, enfermidades, morte, angústias e martírios de toda ordem. Goldring prefere, antes, ressaltar a fragilidade de um corpo-imagem crivado de virtualidades: um ressalto, ainda que microscópico, da silhueta pode levar do horrível ao jocoso. Razão, pois, para privilegiar os momentos de idiossincrasia, quando um corpo em particular permite dizer algo sobre o corpo em geral. Para que ele faça sentido, é preciso que se empregue na astúcia de fazer derivar sentidos; é preciso que não concentre sentidos, mas aspire a certa insensatez com o fito de universalidade. Razão, pois, para apostar na parceria com dançarinos: antes de se darem gratuitamente ao espetáculo, seus corpos "fazem as provas", por assim dizer, de si mesmos. As imagens que produzem são verdadeiras justamente porque não procuram aderir a algo que Ihes preexiste. A dança é, para Goldring, um dispositivo de construção por meio da imagem.

Tal fica evidente no trabalho que Goldring desenvolveu em 1998 com o dançarino-coreógrafo Xavier Le Roy, no solo Self-Unfinished. ${ }^{5}$ Ali, graças a uma dramaturgia de movimentos atenta em repensar gestos do cotidiano, acrescida de sutilezas perceptivas, vê-se uma pletora de epifanias imaginárias que

FONTES FILHO, Osvaldo. Os Corpos Insensatos de Laurent Goldring

PóS:Revista do Programa de Pós-graduação em Artes da EBA/UFMG. V.9, n.18: nov.2019

Disponível em < https://eba.ufmg.br/revistapos $>$

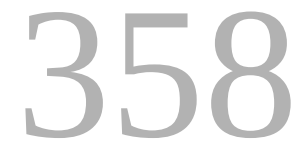


perturbam a visão focal e o reconhecimento formal. O cenário é despojado ao máximo; somente uma mesa e uma cadeira em um white cube. O dançarino não conta com qualquer artifício teatral (iluminação ou cenário): é a performance, em sua lógica especulativa, que se impõe. Inicialmente, essa se faz como uma neutralização da evidência naturalista de alguns gestos banais como o sentar, o andar, o se alongar, etc. São gestos de clara desafecção estilística, "gestos sem melodia, sem acento nem fraseado" (BOUVIER, 2015, p. 2). A intenção é a de romper com as expectativas do público, e não avançar para além de movimentos atonais. Supor-se-ia, sem grandes equívocos, que não estão longe os procedimentos cronofotográficos de Marey e de Muybridge que, em fins do século 19, procuraram discriminar os movimentos intensivos do corpo humano. Como se se tratasse de reunir as condições experimentais propícias a uma analítica dos gestos e, em consequência, uma objetivação do olhar, redutível ao simples ato de "leitura" das cenas. Ocorre, porém, que os esquematismos corporais que se seguem na performance de Le Roy ganham uma plasticidade metamórfica: modo de evidenciar a natureza incircunscritível, instável, do corpo. Com efeito, na sequência surge em cena uma série de anamorfoses corporais, aberrações morfológicas que Le Roy diz ser uma "viagem do corpo rumo a seu

próprio caos" (apud BOUVIER, 2015, p. 4). Rompido o esquematismo mecânico, o gestual pode invocar perturbadores ritmos inumanos. Em adição às torções próprias ao exercício da dança em sua acepção mais geral, o dançarino-coreógrafo constrói novos sentidos (novas estases?) para as representações imaginárias do corpo. Um ardil do vestuário permite que cabeça e tronco se escamoteiem, liberem espaço cênico para membros inferiores e superiores, que passam a compor aberrante figura, entre o aterrador e o burlesco. Um corpo assim reconfigurado em suas possibilidades anatômicas (que não deixam de remeter às surrealistas criaturas de Hans Bellmer) perambula em cena, indife-

FONTES FILHO, Osvaldo. Os Corpos Insensatos de Laurent Goldring

PóS:Revista do Programa de Pós-graduação em Artes da EBA/UFMG. v.9, n.18: nov.2019

Disponível em < https://eba.ufmg.br/revistapos $>$

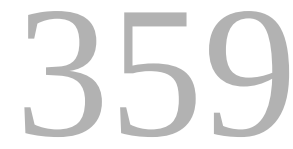


rente às restrições da horizontalidade do chão e da verticalidade da parede. Por fim, desnudando-se, esse corpo que se deu a tantas formas espantosas torna-se massa informe, carne que despenca da parede - impossível ignorar alusão aos crucifixados de Bacon -, apoiada sobre a parte posterior da cabeça e dos ombros (FIGURAS 2 e 3 ).

A performance entende ultimar uma subtração de si, ou melhor, uma recomposição de si com o espaço e os objetos. Testemunha Le Roy (2014, p. 166), "Quando repouso junto à parede, torno-me o contato entre a parede e meu corpo, entre o chão e meu corpo. [...] Procuro me tornar a linha horizontal na qual minha massa e volume desaparecem entre o chão e a parede". Daí se concluir que a imagem não diz respeito à imobilidade, mas à recomposição de relações entre a figura humana e as coisas. Yvonne Rainer, a emblemática autora de Trio A (1966), solo que mudou o fraseado do gesto dançado, emitiu a justa apreciação de tal espetáculo: o que impede que a encenação de tais "esquisitices biomórficas" se assemelhe a algum espetáculo de entretenimento das massas é o fato de ela exigir uma particular atenção do espectador para o que se revela um "timing refinado". 6 De fato, o observador implicado nesse tipo de performance - "desejava que a participação do espectador consistisse em questionar o que ele percebia" (LE ROY, 2011, p. 20) - é instado a uma atenção renovada sobre as potencialidades figurais que o corpo do performer libera. Figural, porque a imagem aqui se quer não figurativa; a forma proposta seria assim, nas palavras de Jean-François Lyotard, uma "anti-boa forma”, um acontecimento "abrindo um espaço e um tempo de vertigem [não] atrelados a seu contexto ou a seu ambiente perceptivo". (apud HUESCA, 2011, p. 137).

A compreensão da figura como acontecimento visual não icônico segue uma tradição da filosofia da arte francesa que passa por Louis Marin, Daniel Arasse e, mais recentemente, por Georges Didi-Huberman e Marie-José Mondzain. Nos

FONTES FILHO, Osvaldo. Os Corpos Insensatos de Laurent Goldring

PóS:Revista do Programa de Pós-graduação em Artes da EBA/UFMG. v.9, n.18: nov.2019

Disponível em < https://eba.ufmg.br/revistapos $>$

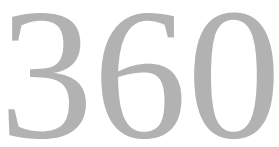


passos da metapsicologia freudiana, esses autores - matéria de leitura por parte de Goldring - mostram como os desvios significantes da figura (na iconografia cristã e na modernidade), com seus processos tropológicos de deslocamento, condensação e travestimento, são comparáveis ao trabalho da figurabilidade que Freud descrevia como uma das artimanhas do inconsciente, donde o reconhecimento, nas visualidades aqui apresentadas, dos engajamentos plásticos do sonho e do sintoma.

A figurabilidade plástica que anima as imagens de Goldring recebeu confirmação recentemente em uma produção coreográfico na qual ele colabora com a performance da bailarina Eva Klimackova. Ouvrir le temps (the perception of) ${ }^{7}$ é uma obra na qual, uma vez mais, as figurações surgidas do corpo dançado não são motivadas pelo referente imaginado. Coreógrafo e dançarina partilham aqui uma mesma heurística, que entendem desestabilizar o olhar do espectador. Efetivamente, esse é instado a acompanhar a produção incessante de movimentos, muitos deles saídos de banalidades gestuais, sem que possa se favorecer de alguma continuidade narrativa. As evoluções da dançarina ocorrem sem música, mas na escuta, de tempos em tempos, da poesia de Gherasim Luca (1913-1994). Essa combina uma coleção de motivos de base, invariavelmente graves: as angústias, o vazio, a morte. O poema (Le chant de la carpe, 1986) corre ao ritmo mântrico de uma voz instrucional: "erguer em conjunto as ideias / sem atingir a vertical / e trazer ao mesmo tempo a vida diante do vazio bem estendido"; "não retirar o vazio do solo / conservar ideias e morte estendidas"; "vergar a morte para a esquerda"; "manter as angústias atrás". Notável é o modo como a composição do movimento coreográfico não obedece literalmente a tais injunções vindas de uma textualidade sobre a qual a princípio ela se assenta. O gesto da dançarina, por vezes, é simples (um braço que pende, a cabeça que se apoia); por vezes, investe exuberante contorcionismo (um brusco balouçar das pernas, um braço que partilha com os pés a função de apoio). A transição de um registro a outro se dá de modo invariavelmente intransitivo, dir-se-ia arborescente. Sente-se um

FONTES FILHO, Osvaldo. Os Corpos Insensatos de Laurent Goldring PóS:Revista do Programa de Pós-graduação em Artes da EBA/UFMG. v.9, n.18: nov.2019 Disponível em < https://eba.ufmg.br/revistapos $>$ 
afobamento do olhar. Uma mão que surge por detrás de um pé, lá onde não a julgaríamos capaz de ir; um pé que parece constituir terceira mão num equilibrar atlético do corpo na posição invertida, e assim por diante (FIGURA 4).

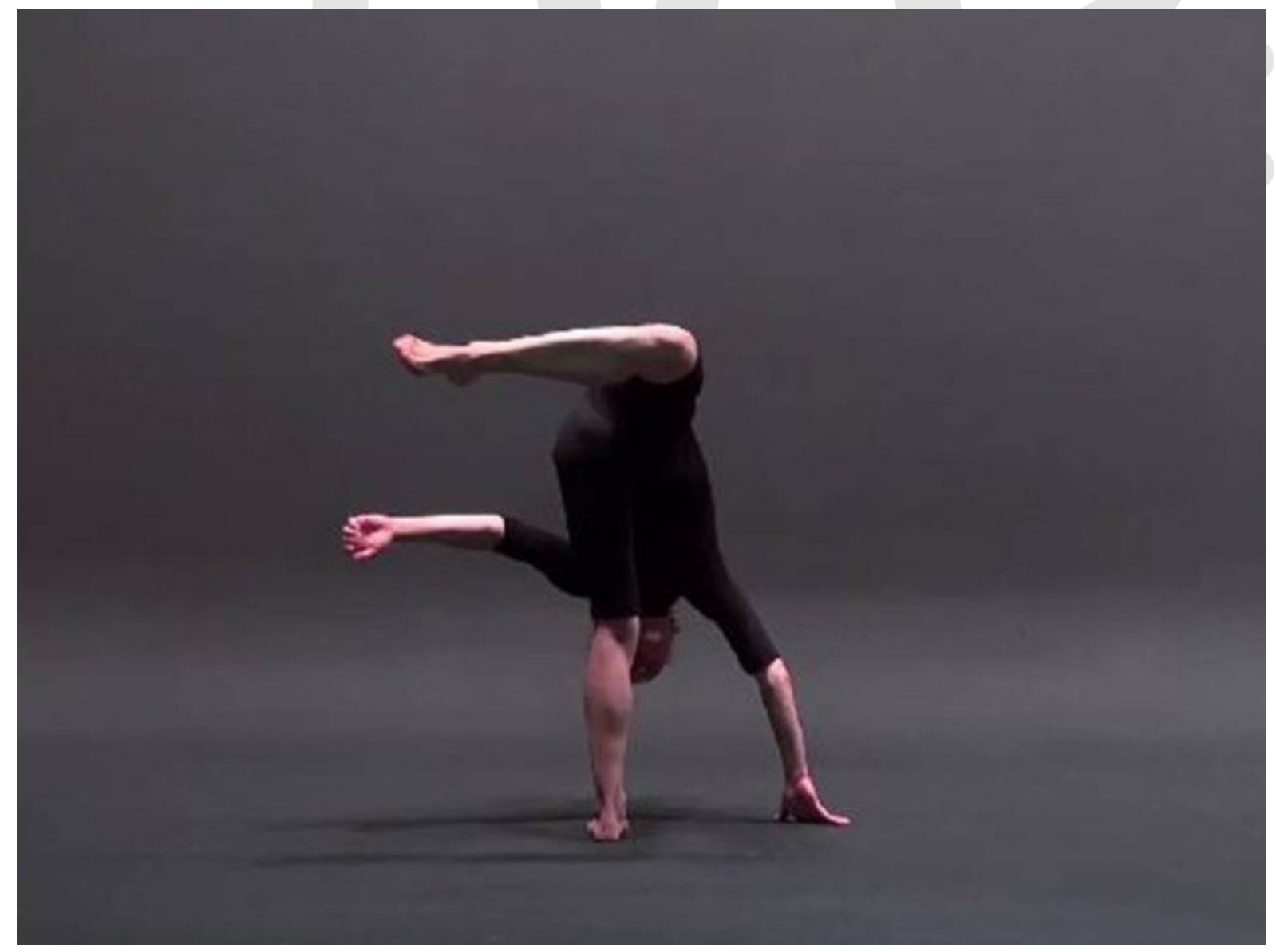

Figura 4 - Eva Klimackova, Ouvrir le temps (the perception of), performance solo - 2016 Fonte: https://vimeo.com/187272260.

Não é propósito encadear meras ilusões óticas. O gesto retido em fotografia falseia mesmo a intencionalidade motriz aqui posta em cena: coreógrafo e dançarina partilham o mesmo anseio em reprimir o desejo, mais ou menos consciente, de uma imagem resolvida em sua premeditada plasticidade. Na plena cumplicidade com as reivindicações mais prementes da dança contemporânea, Goldring produz uma escritura gestual que, à semelhança da poesia de 
Gherassim Luca, (des)articula signos, à beira da abstração, para rearticulá-los em inusitados fluxos. Razão porque os gestos de Eva Klimackova mostram-se pregnantes, ou melhor, descontraídos, mesmo imperfeitos. Sente-se que, entre a dançarina e o coreógrafo, a consciência imagética das figuras hesita, a dança gagueja em sua própria língua, modo de produzir seus outros possíveis.

FONTES FILHO, Osvaldo. Os Corpos Insensatos de Laurent Goldring PóS:Revista do Programa de Pós-graduação em Artes da EBA/UFMG. v.9, n.18: nov.2019 Disponível em < https://eba.ufmg.br/revistapos $>$ 


\section{REFERÊNCIAS}

AGAMBEN, Giorgio. Uso dos corpos [Homo Sacer, IV, 2]. Trad. Selvino J. Assmann. São Paulo: Boitempo, 2017.

BELLOUR, Raymond. L’Entre-Images. Photo, Cinéma, Vidéo. Paris: La Différence, 1990.

BLANCHOT, Maurice. A conversa infinita 2: A experiência limite. Trad. João Moura Junior. São Paulo: Escuta, 2007.

BOUVIER, Mathieu. Excès de vision, Self Unfinished de Xavier Le Roy. Corps-Objet-Image, Strasbourg, n. 1, 2015. Disponível em: http://www.pourunatlasdesfigures.net/element/excesde-vision-self-unfinished-de-xavier-le-roy. Acesso em: 10 set. 2018.

CHARLIN, Sophie. Blocs frissonants. Balthazar, n. 5, p. 74-75, mar. 2002. Disponível em: http://www.laurentgoldring.com/images/selected_press/dossier_presse-court_2014.pdf. Acesso em: 5 set. 2018.

DEBAT, Michelle. L'impossible image.Photographie - Danse-Choréographie. Paris. La lettre volée, 2009. Disponível em:

http://www.laurentgoldring.com/images/selected_press/dossier_presse-court 2014.pdf. Acesso em: 4 set. 2018.

DELVAL, Florent. Laurent Goldring, Images indivisibles. Mouvement, n. 46, jan.-mar. 2008, p.117-121.

GOLDRING, Laurent. Images en formation. Entretien avec Laurent Goldring: propos recueillis par Cyril Béghin et Stéphane Delorme, Balthazar, n. 5, mar. 2002, p. 77-85. Disponível em: http://www.pourunatlasdesfigures.net/wp-content/uploads/2018/01/2002-03Goldring-balthazar-entretien.pdf. Acesso em: 31 ago. 2018.

GOLDRING, Laurent. Les bodymades de Laurent Goldring ; Just the Body. Entretien avec Jacqueline Caux. Art Press, n. 242, p. 40-43, jan. 1999.

GOLDRING, Laurent. Hypothèse numéro huit. L'auteur de la ressemblance. Revue LIGEIA, Dossiers sur l'Art, n. 49-52, La photographie en vecteur, Jan.-Juin 2004. Disponível em: http://www.pourunatlasdesfigures.net/element/hypothese-numero-huit-lauteur-de-laressemblance. Acesso em: 1 set. 2018.

GOLDRING, Laurent. Hypothèse numéro quatre: La liquidation du modernisme. Les Nouvelles d'Archimède. Revue culturelle de l'Université Lille 1, n. 65, 2014.

GOLDRING, Laurent. Le cinéma fait son spectateur. In: FÉRAL, Josette (dir.). Pratiques performatives. BodyRemix. Rennes: Presses Universitaires de Rennes. p. 113-124, 2012.

FONTES FILHO, Osvaldo. Os Corpos Insensatos de Laurent Goldring

PóS:Revista do Programa de Pós-graduação em Artes da EBA/UFMG. v.9, n.18: nov.2019

Disponível em < https://eba.ufmg.br/revistapos $>$ 
Disponível em: http://www.pourunatlasdesfigures.net/element/hypothese-4-bis-le-cinema-faitson-spectateur. Acesso em 10 set. 2018.

GOUMARRE, Laurent. Pour une esthétique de la posture. Art Press, n. 282, 2002.

HUESCA, Roland. Nudité, corps et "figure ". L'exemple chorégraphique. Nouvelle revue d'esthétique, n. 8, p.136-143, 2011. Disponível em: https://www.cairn.info/revue-nouvellerevue-d-esthetique-2011-2-page-136.htm. Acesso em: 6 set. 2018.

LE ROY, Xavier. Penser les contours du corps (entretien avec Xavier Le Roy, recolhida por Jacqueline Caux). Art Press, Paris, n. 266, p. 19-21, 2001. Disponível em: < http://www.jacquelinecaux.com/download/articles/penser_les_contours_du_corps_entretien avec_xavier_le_roy_art_press_mars_2001_n266.pdf >. Acesso em: 8 set. 2018.

LE ROY, Xavier. Retrospective Xavier Le Roy. Dijon: Les presses du réel, 2014. Disponível em: http://www.laurentgoldring.com/images/selected_press/dossier_presse-court_2014.pdf. Acesso em: 9 set. 2018.

LOUPPE, Laurence. Danse-photographie: pour une théorie des usages. Art Press, n. 281, p. 47-52, agosto 2002. Disponível em:

https://www.artpress.com/wp-content/uploads/2014/12/2077.pdf. Acesso em: 8 set. 2018.

PARFAIT, Françoise. Les images freinées (Actualité du neutre). Ligeia, p.151-157, jan.-jun. 2004.

PERRIN, Julie. Ler Rancière a partir do campo da dança contemporânea. AISTHE, v. 7, n. 11, p. 42-60, 2013.

PLANTIN, Marie. Les images primitives de Laurent Goldring sont à la Galerie Maubert, Pariscope, 2017. Disponível em: http://www.pariscope.fr/base/les-images-primitives-delaurent-goldring-sont-a-la-galerie-maubert. Acesso em: 10 set. 2018.

RANCIÈRE, Jacques. A partilha do sensível. Estética e política. Trad. Mônica Costa Netto. São Paulo: Ed. 34, 2005.

RANCIÈRE, Jacques. Aisthesis. Scènes du régime esthétique de l'art. Paris: Galilée, 2011.

VOLLAIRE, Christiane. Danse contemporaine : les formes de la radicalité. In Anne Boissière \& Catherine Kintzler (ed.), Approche Philosophique du Geste Dansé: De l'Improvisation à la Performance. Presses Universitaires du Septentrion, 2006. p. 179-201. Disponível em: http:// lesilencequiparle.unblog.fr/2013/11/14/danse-contemporaine-les-formes-de-la-radicalitechristiane-vollaire/. Acesso em: 12 set. 2018.

FONTES FILHO, Osvaldo. Os Corpos Insensatos de Laurent Goldring

PóS:Revista do Programa de Pós-graduação em Artes da EBA/UFMG. v.9, n.18: nov.2019

Disponível em < https://eba.ufmg.br/revistapos $>$

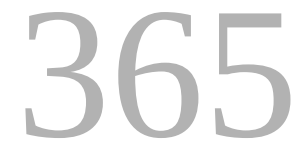




\section{NOTAS}

1 Algumas das imagens exibidas em 2002, acrescidas de outras, foram recentemente exibidas na Galeria Maubert, em Paris, em exposição que levava o título "Mouvement premier, Corps insensés", que em parte retivemos para o título do presente texto.

2 Vídeo disponível em: https://vimeo.com/77638210.

3 Vídeo disponível em: https://vimeo.com/32040751.

4 Importa, porém, ressaltar a crítica que Goldring faz do modernismo como entronização de ume "especificidade absoluta" da arte, modo de autoproteção contra o novo estatuto das imagens em sua difusão virtual desenfreada. A imagem que Goldring preconiza se faz na contrafação do "imediatamente reconhecível", modelo para as imagens comerciais. "L'art moderne est né du refus de participer à ces batailles d'images qui se jouent sur la quantité d'occurrences. L'art n'a pu conserver sa spécificité qu'à refuser ce devenir redondant avec le monde des signes, et ce refus a été celui de la circulation entre les mediums. La recherche des spécificités a été la seule protection efficace contre la disparition de l'art comme autre monde possible" (GOLDRING, 2014, p. 28). O sentimento de um "vacilo da mimesis", ordinariamente atribuído às imagens analógicas, data dos primeiros vídeos de Bill Viola, adepto de uma estética do entre-imagens. Motivo que Raymond Bellour teoriza como o lugar de passagem das imagens, hoje; entre imobilidade e movimento, figuração e desfiguração (BELLOUR, 1990). Eis o lugar de eleição das imagens de Goldring.

5 Parcialmente disponível em: https://vimeo.com/22034064.

6 Yvonne Rainer em e-mail enviado a Xavier Le Roy, em 22/12/1999, citado no site do artista: http://www.xavierleroy.com.

7 Parcialmente disponível em: https://vimeo.com/187272260. 